\title{
ENGLISH-JAPANESE TRANSLATION THROUGH CASE-STRUCTURE CONVERSION
}

Fujio Nishida, Shinobu Takamatsu and Hiroaki Kuroki

Department of Electrical Engineering,

Faculty of Engineering, University of Osaka Prefecture, Sakai, Osaka, 591 JAPAN

This paper reports some trials on mechanical translation from English to Japanese through a case structure constructed on Homby's verb patterns. Though the general theoryof case structures is still at the beginning of study, it provides partial sentential pattems with rough but resonable classification labels. After determination of schematic dependency relations, multi-vocal problems for choosing appropriate equivalents are dissolved using subcategories of terms and cases. Case structures of English are transformed into those of Japanese if necessary, and from those, Japanese sentences are generated by a Japanese grammar.

\section{Introduction}

English and Japanese are fairly different languages from each other. Accordingly, it will be necessary to make translation based on a kind of deep structures of sentences which determines sentential forms schematically in respective languages. The case structure used here is a conventional one which is closely related to surface structures. But it was found that the case structure is fairly useful by adding some new means in construction and usage of it.

The parsing for obtaining the case structure from English sentences is done by category-matching on a fairly precise verb pattern given by. A.S. Hornby. It dissolves most of multi-syntactic and semantic category problems of words and phrases, and determines global dependency relations among constituents of English sentences.

Subsequently, it determines the appropriate Japanese equivalents and postpositions among several candidates by using subcategories of terms and individual prepositional words.

The case structure thus obtained containes the modal part which represents various characteristics of the predicate part in almost independent form of respective languages. It also embeds idiomatic expressions in itself.

At the level of the case structure, the difference between both language expressions is not so large. Transformations of sentential forms such as those of non-living subjects and those of principal clauses followed by long subordinate ones for readability are processed at this stage without difficulty. From the case structures transformed into Japanese, translated sentences are generated under control of various involved parameters.

\section{Case structures}

\subsection{Case structures of verbs}

Many English words have multi-syntactic and semantic categories. However, these multi-categories of a word in a sentence should be able to be dis -solved in a context of the sentence, namely, in syntactic and semantic relations to the neighboring words. A.S. Hornby has given comparatively precise verb patterns. ${ }^{3}$ The use of verb patterns at parsing is fairly effective to identify the syntactic categories of words and phrases as well as their syntactic roles such as complements and adverbial infinitives.

On the other hand, an efficient introduction of semantic information about words is very important in order to identify thein semantic roles and appropriate Japanese equivalents as well as to dissolve the still remaining syntactic ambiguities after a syntactic analysis. For this purpose, there are several approaches based on the case grammar. "It is still in an incomplete state for general purpose of thorough comprehension of sentences. But if it is used on detailed syntactic rules of the conventional word usage with the aids of categories of an appropriate level at various stages of mechanical translation, these approaches based on the case gramar will serve fairly well to assign reasonable

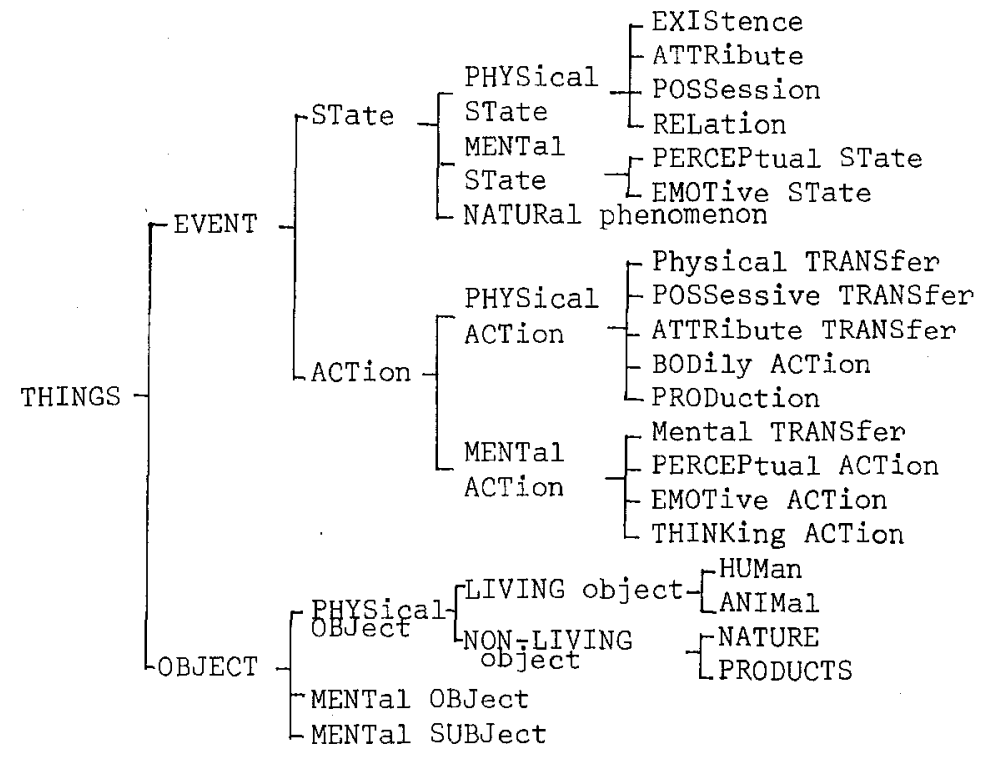

Fig.1 The upper part of the categorical trees. 
semantic roles to various constituents in a source sentence as well as to choose their appropriate equivalents and sentential forms in the target language.

From the above considerations, a case structure is assigned to a sentence based on Hornby's verb patterns.

Events of discourse are classified by categories of predicates. Fig.1 shows the upper part of the categorical tree used here. The categories used for describing case structures are, in many cases, those appearing at the rightmost in Fig.l.

Semantic roles of constituents are described using case labels shown in Table 1 .

\section{Table 1 Case labels}

PREDicate, AGent, OBJect, EXPERiencer, RECIPient, SOurce, GOal, INSTRument, DEGree, COMPARison, LOCation, TIME, RANGE, MANNer, ROLE, CAUSE, RESULT, MEANS, PURPOSE, CONDition, MODal (FORM, TENSE, ASPECT, AFfirmation, MOOD, VOICE ), ...

By using several pains of categories and case -labels chosen from the above the main parts of each event are schematically described and called case-frames of events. The first row of Table 2 is the main case-frame of the PTRANS event.

The main part of a case structure based on a case-frame is transformed into a surface structure using a verb which has a sufficient number of

Table 2 Case-frame of PTRANS action and assignment of verb patterns

\begin{tabular}{|c|c|c|c|c|c|c|}
\hline $\begin{array}{l}\text { PRED- } \\
\text { PTRANS }\end{array}$ & $\begin{array}{l}\text { AG- } \\
\text { THINGS }\end{array}$ & $\begin{array}{l}\text { OBJ- } \\
\text { PHYS OBJ }\end{array}$ & $\begin{array}{l}\text { GO- } \\
\text { LOCAT U } \\
\text { PHYS OBJ }\end{array}$ & $\begin{array}{l}\text { DEG- } \\
\text { QUANT }\end{array}$ & $\begin{array}{l}\text { PURPOSE } \\
-\mathrm{ACT}\end{array}$ & $\begin{array}{l}\text { MANN } \\
-A C T\end{array}$ \\
\hline VP2B & \multirow{4}{*}{$\begin{array}{r}\text { SUBJ- } \\
\text { ect }\end{array}$} & - & - & $\begin{array}{c}\text { ADVer } \\
\text {-bial } \\
\text { Adjunct }\end{array}$ & - & - \\
\hline VP2E & & - & — & 一 & - & $\begin{array}{l}\text { PResent } \\
\text { PARtici } \\
\text {-ple }\end{array}$ \\
\hline VPI $2 A$ & & \multirow{2}{*}{$\begin{array}{l}\text { Direct } \\
\text { Object }\end{array}$} & $\begin{array}{l}\text { Indirect } \\
\text { object }\end{array}$ & - & $\longrightarrow$ & - \\
\hline VP16A & & & - & - & $\begin{array}{l}\text { to-INF- } \\
\text { initive }\end{array}$ & - \\
\hline$!$ & $:$ & $!$ & $\vdots$ & $:$ & $:$ & 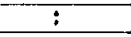 \\
\hline
\end{tabular}

Table 3 Case structures of verb pattern VP12A

\begin{tabular}{|c|c|c|c|}
\hline VPI2A & SUBJ & IO & DO \\
\hline $\begin{array}{l}\text { PRED- } \\
\text { PTRANS }\end{array}$ & $\begin{array}{l}\text { AG- } \\
\text { THINGS }\end{array}$ & $\begin{array}{l}\text { GO- } \\
\text { LOCAT } \cup \\
\text { PHYS O OBJ }\end{array}$ & $\begin{array}{l}\text { OBJ- } \\
\text { PHYS } \cdot \text { OBJ }\end{array}$ \\
\hline $\begin{array}{l}\text { PRED- } \\
\text { POSS - TRANS }\end{array}$ & $\begin{array}{l}\text { AG- } \\
\text { HUM }\end{array}$ & $\begin{array}{l}\text { RECIP- } \\
\text { HUM }\end{array}$ & $\begin{array}{l}\text { OBJ- } \\
\text { OBJECT }\end{array}$ \\
\hline $\begin{array}{l}\text { PRED- } \\
\text { MTRANS }\end{array}$ & $\begin{array}{l}\text { AG- } \\
\text { HUM }\end{array}$ & $\begin{array}{l}\text { EXPER- } \\
\text { HUM U } \\
\text { MENT·SUBJ }\end{array}$ & $\begin{array}{l}\text { OBJ- } \\
\text { EVENT U } \\
\text { MENT } \text { OBJ }\end{array}$ \\
\hline
\end{tabular}

links to describe the main part and belongs to an appropriate verb pattern. Table 2 shows verb patterns used for English description of PTRANS.

on the other hand, if a verb pattern is given, pairs of categories and case labels of dependants are almost determined every category of the predicate verb as shown in Table 3 . Hence, if the verb patterns as well as the categories of a verb are recorded in a word dictionary, the possible case structure can be retrieved at parsing immediately. Table 4 shows a part of pairs of verb patterns and categories about 'take'.

Example 1 shows several examples of case structures obtained by parsing with the aids of Table 4.

After determination of a case structure on a dependency relation of a sentence, there still remain several problems to be solved.

One of them is the choice of an appropriate equivalent or a subcategory. The word 'take' with the verb pattern VP6A and the case structure has fairly many Japanese equivalents. However, this kind of multi-vocal problems can be dissolved in many cases by looking up subcategories of a few designated dependants involved in the case structure and hence in advance by recording them for each equivalent in the word dictionary as shown in Table 4.

The other is the choice of an appropriate Japanese postposition corresponding to a case label and a category of a dependant of a verb. Though a good correspondence generally holds between them, there are some exceptions. For these cases, the postposition is recorded at the item of the associated verb in the dictionary and picked up at parsing.

Example 1

(1) VPGA : BODily ACTion

'He took bread.'

(PRED-BOD・ACT : eat, MOD: (TENSE: past ,VOICE : active), AG-HUM: he, OBJ-

EOOD:bread )

'He took a taxi?'

(PRED-BOD-ACT: get-on, MOD: (TENSE: past, VOICE: active), AG-HUM: he, OBJ-VEHICLE : a-taxi)

(2) VP6A : Mental TRANSfer

'I took his speech.'

(PRED-MTRANS : make-a-record-of, MOD: (TENSE: past, VOICE: active), AG-HUM:I, OBJ-EVENT:his-speech)

(3) VP15A : Physical TRANSfer 'I took the children to the park.' (PRED-PTRANS:go-leading, MOD: (TENSE:past, VOICE: active), AG-HUM:I, OBJ-HUM: the-children, GO-LOCAT: the-park) 
Table 4 A part of the item 'take' in the word-dictionary

\begin{tabular}{|c|c|c|}
\hline Verb patterns & Categories & Meanings ( and the designated conditions) \\
\hline \multirow[t]{5}{*}{ VP6A } & $B O D \cdot A C T$ & $\begin{array}{ll}\text { 1. get into one's hand } & (\text { OBJ-PHYS OBJ ) } \\
\text { 2. eat } & (\text { OBJ-FOOD ) } \\
\text { 3. get on } & (\text { OBJ-VEHICLE ) } \\
\text { : } & \end{array}$ \\
\hline & PTRANS & $\begin{array}{ll}\text { 1. go carrying } & (\text { OBJ-NON-LIVING }) \\
2 . \text { go leading } & (\text { OBJ-LIVING }) \\
\end{array}$ \\
\hline & POSS - TRANS & ( OBJ-COMMODITY ) \\
\hline & MTRANS & $\begin{array}{c}\text { 1. make a record of } \\
\vdots\end{array}$ \\
\hline & $:$ & $:$ \\
\hline VP22 & $\mathrm{PERCEP} \cdot \mathrm{ACT}$ & $\begin{array}{c}\text { 1. suppose } \\
\vdots \\
\end{array}$ \\
\hline : & : & : \\
\hline
\end{tabular}

(4) VP22 : PERCEPtual ACTion

'I took her intelligent."

(PRED-PERCEP-ACT: suppose, MOD: (TENSE: past,

VOICE: active), EXPER-HUM:I, OBJ-EVENT:

(PRED-ATTR: intelligent, OBJ-HUM:she))

\subsection{Optional cases}

Adverbial phrases and clauses outside verb patterns constitute optional cases. Most of idiomatic phrase prepositions such as 'with respect to' and many subordinate conjunctions such as 'when' and 'although' determine the case labels and the Japanese postpositions of the following phrases and clauses. On the other hand, many prepositional phrases which respectively have only one prepositions such as 'with' and 'for' require the information about frame of discourse for determination of the case label and the appropriate Japanese postposition. These information is the categories of the object term of the phrase and those of main verb of the governor and funthermore, in some cases, other information about case structure of the verb pattern.

For example, an adverbial phrase consisting of a prefixed preposition 'in' and an object term with category'PHYSical LOCation' can be assigned a case label'LOC' or 'GOal', but the appropriate postposition and case label are determined by referring to the semantic category of the main verb.

The necessary information for determining them are recorded each preposition and subordinate conjunction in the word dictionary.

\subsection{Case structures of noun phrases and clauses}

Case structures of noun phrases and clauses have similar forms to those of sentences as follows;

$$
t\left(K_{1}-C_{1}: t_{1}, \cdots, K_{i}-C_{i}: t, \cdots, K_{n}-C_{n}: t_{n}\right)
$$

where $t$ is the main term, $t_{j} s$ are the dependants and $K_{j}-C_{j}$ is a pair of a case label and a category.

The case structure only consisting of several individual objects and prepositions are determined by referring to the categories of the objects and their syntactic patterns linked with the individual prepositions.

If a noun phrase contains some verbal nouns, the case structure is constructed based on the verbalized words of some of them.

Example 2

(1) 'receipt of his letter"

C-EVENT: receive(PRED-POSS-TRANS: *, OBJ-PHYS•OBJ : letter (OBJ : *, POSS-HUM:his))

(2) 'punctual arrival of trains' C-EVENT: arrive(PRED-PTRANS: *, AG-VEHICLE: trains, MANN-MODAL: punctual)

where $C$ denotes a certain case for the outside governor and the symbol * denotes the prefixed term to the case frame containing it.

\section{Parsing}

First, processing of negative expressions and idioms are described. They are processed in a somewhat special manner.

\subsection{Negative expressions}

Negative expressions of English are fairly different from those of Japanese at the points where negative adjectives or adverbs of English correspond to some negative modifiers and a negative auxiliary verb in Japanese. Hence, it 
will be better to express the negative expression of an English sentence in a language-free form at the modal part of the case structure and to generate the corresponding Japanese sentence from that anew. The types of NEGation are classified to INTensified TOTal, TOTal and PARtial ones.

At parsing, the value of type is put in the modal part of the case structure together with the terms directly negated except the case when the terms belong to the predicate part of the sentence.

Example 3

(1) 'No student can solve the problem? (PRED-THINK·ACT : solve, MOD: (AF: ( INT·TOT·NEG, student), MOOD:can), AG-HUM:student, OBJ -MENT•OBJ : problem(OBJ:*, DET:def))

(2) 'Converses are not always true.' (PRED-ATTR: true, MOD: (AF:(PAR.NEG, always)), OBJ-MENT. OBJ : converses, FREQuency: always )

Most of terms of modal cases are omitted here and hereafter except important terms for simplicity.

\subsection{Idiomatic expressions}

For an efficient parsing, idiomatic expressions are processed with scme priority. They are recorded near the heading of the leftmost word among multivocal constituents of the idiom in the word dictionary. If the idiom has a separated form $t_{1} \sim t_{2}$ as shown in Eq. (2),

$$
t_{1} s_{1} \cdots s_{n} t_{2}
$$

the syntactic and semantic conditions on the strings of words or phrases $s_{1}, \ldots, s_{n}$ lying between $t_{1}$ and $t_{2}$ are recorded together with the partial case structure and the Japanese equivalent of the idiom in the word dictionary as follows:

so $\Delta_{1}$ that $\partial_{2}$

(DEG-QUALity: so[ADVerb] very*, PRED-ATTR: $\phi_{1}$ [ADJective], RESULT(that[SUBORDinate cONJunction])-EVENT : $\$_{2}$ [SENTence]),

where 'very' denotes the Japanese word equivalent to the English word 'so'.

When a constituent word. of an idiom is found in a sentence at parsing, it is examined whether or not there exist the rest parts of the idiom in the sentence by reading the sentence ahead or by examining the partial case structure already constructed. If there is, and if the intermediate part $s_{1} \cdots s_{n}$ satisfies specified conditions by parsing, the partial case structure and the Japanese equivalent of the idiom are added to those already constructed by referring to the word dictionany. Otherwise, ordinary mode of parsing restarts from term $t_{1}$.

\section{Example 4}

'The problem was so difficult that he could not solve i.t." (PRED-ATTR: difficult, OBJ-MENT. OBJ : problem(OBJ: *, DET: deF), DEG-QUAL:so(very), RESULT-EVENT: (PRED-THINK•ACT: SOlve, MOD: (AF:TOT•NEG, MOOD:

can), AG-HUM:he, OBJ-THINGS:it))

\subsection{Construction of case structures}

The rewriting rules used for parsing are described in a Chomsky-like form as follows;

$$
\begin{aligned}
& V_{1}\left(K_{1}-C_{1}: t_{1}, K_{2}-\mathbb{C}_{2}: t_{2}\right) \\
& \rightarrow v_{2}\left(K_{1}-c_{1}: t_{1}\right) v_{3}\left(\mathbb{K}_{2}-\mathbb{C}_{2}: \mathbb{t}_{2}, \mathrm{VP}_{i}\right) \\
& V_{3}\left(K_{2}-\mathbb{C}_{2}: t_{2}, K_{3}-C_{3}: t_{3}, V P i\right) \\
& \rightarrow V_{4}\left(\mathbb{K}_{2}-\mathbb{C}_{2}: \mathbb{U}_{2}, \mathrm{VP} i\right) \mathrm{V}_{5}\left(\mathrm{~K}_{3}-\mathrm{C}_{3}: \mathrm{t}_{3}\right)
\end{aligned}
$$

where $V_{i}(i=1 \sim 5)$ denotes a non-terminal symbol, $\mathbb{K}-\mathbb{C}: \mathbb{Z}$ a sequent of several pairs of a case label and a category followed by a term, and VPi a label of a verb pattern.

Eq. (3) represents the type of rewriting rules of a subject and a predicate part, and Eq.(4) that of a predicate part and a right dependent.

The parsing is done from left to right in a bottom-up manner and case structures are constructed in the order of the predicate part, the right part of a verb pattern of the predicate part, the subject part and the optional adverbial parts. This order is considered to be efficient for restricting possible construction of case structures of many sentences of English because the central structure is generally constructed in this order.

At first, the partial case structure of the predicate part is constructed. If the main verb is a constituent of an idiom, parsing is done in a manner described in the preceding section. otherwise, all the case structures for the verb patterns are constructed using the word dictionary and a table of case frames.

When a main term $t_{i}$ with a category $c_{i}$ comes to be included in a partial case structure $\mathrm{S}_{j}(j=1,2, \ldots, \mathrm{m})$ as shown in Fig.2, syntactic and categorical consistency is checked.

If the consistency holds, the term with the category $C_{i l}$ is added to the partial case structure $\mathrm{S}_{j}$ with a designated case label $\mathrm{K}_{j i}$. And if the case $k_{j i}$ is designated for dissolving multi-Japanese equivalents of the main verb in the case structure $S_{j}$, appropriate Japanese equivalents are extracted by subcategory matching.

Otherwise, if the category $C_{i l}$ of the main term $t_{i}$ does not match one of any partial case structure $S_{j}(\dot{j}=1,2, \cdots, n)$, the category $C_{i l}$ is deleted. Similarly, if a partial case structure requires a main term with a designated semantic category and a designated syntactic category or a position and cannot find the term, the partial case structure is deleted. 


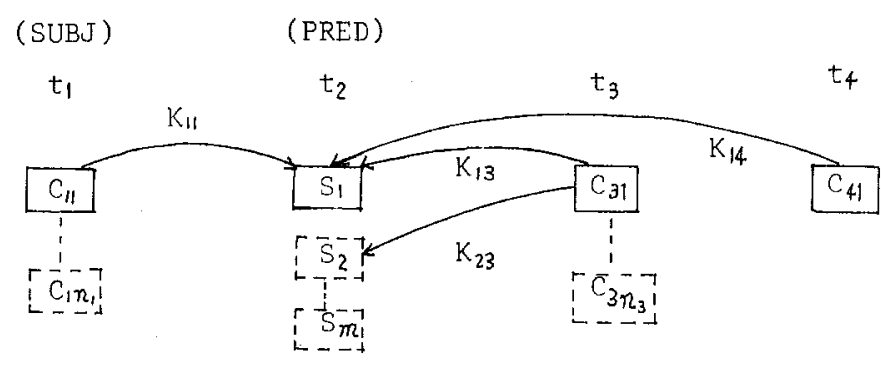

Fig. 2 Construction of case structures

In such a manner, the number of partial case structures decreases or increases as a term is added to partial case structures and, in many cases, it reduces to unity at the end of parsing.

\section{Case transformation}

Some typical differences between English and Japanese sentential forms do not require any case transformation. One of them is negative expressions and processed as already mentioned in section 3.1. The others are compound noun expressions containing some verbal nouns which are prefered to be verbalized in Japanese sentences. However, these Japanese sentences are directly generated from the case structure obtained by parsing since the case structure of a compound noun expression is constructed in the same way as a sentence when it contains some verbal nouns as mentioned in section 2.3 .

Hence, the main differences which require some case transformations are those as mentioned as follows.

4.1 Case transformation for non-causative and state oriented descriptions
Japanese sentences avoid sentential forms in which non-living objects bring actions such as causative and perceptive ones especially when the actions directly affect human beings and some events associated with them. In Japanese, these sentential forms are replaced by noncausative sentences or by resulted-state expressions using state-oriented verbs. This problem is well known as the non-living subject problems and has been fairly well studied by many linguists. 5

It is shown here that the transformation of the expressions can be processed in terms of case structures in a systematic way.

Finst, the value of the voice in the modal case of such a sentence is set passive, because in such a situation a passive form is generally a little bit more acceptable than an active form in Japanese. Second, depending on the category of the main verb and the agent, the agent case is renamed to a more appropriate case so that a more natural Japanese sentence is generated. Third, if possible, the equivalent of the predicate part is modified into a more appropriate form such as state-oriented descriptions.

Some examples of this modification are shown in Table 5.

Table 5 case transformations

\begin{tabular}{|c|c|c|c|}
\hline $\begin{array}{l}\text { Category of } \\
\text { predicate }\end{array}$ & $\begin{array}{l}\text { Instances of } \\
\text { predicate }\end{array}$ & $\begin{array}{l}\text { Case label } \\
\text { for agent }\end{array}$ & $\begin{array}{l}\text { Modification of } \\
\text { predicate }\end{array}$ \\
\hline CAUSE & cause, make & CAUSE & DELetion \\
\hline ENABLE & enable & MEANS & INTRANS VERB \\
\hline ENABLE & allow,permit & $\begin{array}{l}\text { MEANS } \\
\text { CAUSE }\end{array}$ & $\begin{array}{r}\text { REPL by 'capable } \\
\text { verb" }\end{array}$ \\
\hline ENABLE & prevent & $\begin{array}{l}\text { MEANS } \\
\text { CAUSE }\end{array}$ & $\begin{array}{l}\text { REPL by 'not }{ }^{+} \text {, } \\
\text { capable verb* }\end{array}$ \\
\hline $\begin{array}{l}\text { PERCEPtual } \\
\text { ACTion }\end{array}$ & $\begin{array}{l}\text { look } \\
\text { overlook }\end{array}$ & SOURCE & $\begin{array}{l}\text { INTRANS VERB } \\
+ \text { capable verb }\end{array}$ \\
\hline $\begin{array}{l}\text { PERCEPtual } \\
\text { ACTion }\end{array}$ & show & MEANS & $\begin{array}{l}\text { REPL by } \\
\text { 'understand*' }\end{array}$ \\
\hline $\begin{array}{l}\text { EMOTive } \\
\text { ACTion }\end{array}$ & $\begin{array}{l}\text { surprise } \\
\text { please }\end{array}$ & CAUSE & INTRANS VERB \\
\hline
\end{tabular}


The thind column of this table designates some candidates of case labels to be renamed for an agent. The appropriate case label and postposition are determined by the category of the term to be filled.

The fourth column designates the version into which the equivalent of the predicate part is to be modified. The versions are classified into two kinds. One of them is REPLacement of the predicate part by a new intransitive verb.

The other is some modification of a passive Japanese predicate part. The latter is subdivided into DELetion of a causative verb, INTRANSitive VERBalization and addition of the meaning 'capable' to it.

The version is coded and the code is recorded together with a new Japanese intransitive verb for REPLacement in the word dictionary. In Table 5, the words with a symbol * denote the equivalent written in Japanese.

At the execution of case transformation, the routine designated by the code is called and carries out the necessary processing.

\section{Example 5}

By case transformation using Table 5 , two English sentences

(1) "The weight of snow caused the shed to collapse'

and

(2) 'Our limitted budget did not allow us to start a new project'

are translated to Japanese sentences corresponding to

( I') 'Owing to the weight of snow, the shed and collapsed,

(2) 'Owing to our limitted budget, we could not start a new project' respectively.

The main case transformations used here are as follows;

(1) (PRED-CAUSE: cause, AG-QUANT: weight $\left(D_{1}\right)$, OBJ-EVENT : (PRED-PHYS-ACT : collapse, OBJ-PHYS OBJ $:$ shed $\left.\left(D_{2}\right)\right)$ )

$\longrightarrow($ PRED-PHYS-ACT : collapse, OBJ-PHYS.OBJ : shed $\left(D_{2}\right)$, CAUSE-QUANT: weight $\left.\left(D_{1}\right)\right)$

where $D_{1}:=O B J-Q U A N T: *$ DET $:$ def, POSS-PHYS OBJ : snow, $\mathrm{D}_{2}:=\mathrm{OBJ}-\mathrm{PHYS} \cdot \mathrm{OBJ}: *$, DET $:$ def

(2) (PRED-ENABLE:allow, MOD: (TENSE:past, AF: TOT.NEG), AG-QUANT :budget $\left(D_{3}\right)$, OBJ-EVENT: (PRED-ACT : start, AG-HUM: we, OBJ-MENT-ACT : project $\left.\left(D_{4}\right)\right)$

$\rightarrow($ PRED-ACT : start, MOD: (TENSE: past, AF: TOT•NEG, MOOD: can*), AG-HUM:we, OBJ -MENT $A C T$ : $\operatorname{project}\left(D_{4}\right)$, CAUSE-QUANT :budget $\left.\left(D_{3}\right)\right)$

where $D_{3}:=$ OBJ-QUANT $: *$, POSS-HUM:we, PRED-ATTR: limitted, $D_{4}:=O B J-M E N T \cdot A C T: *$, DET $:$ indef, PRED-ATTR: new

Beside the above type of case transformations ,there are miscellaneous types of them. A kind of verbs such as 'bring' requires reference of the category of a term in the object case as well as the one about the recipient on goal case.

A sentence containing a main verb such as 'force' is transformed to a more preferable form in Japanese which has a new manner case filled with a term like 'inevitably' instead of the main verb.

A sentential form which includes the verb 'have' as a main verb is transformed to a more

Table 6 Miscellaneous case transformations

\begin{tabular}{|c|c|c|c|c|}
\hline $\begin{array}{l}\text { Category of } \\
\text { predicate }\end{array}$ & $\begin{array}{l}\text { Instances of } \\
\text { predicate }\end{array}$ & $\begin{array}{l}\text { Referred } \\
\text { case category }\end{array}$ & $\begin{array}{l}\text { Change or } \\
\text { addition of } \\
\text { case }\end{array}$ & $\begin{array}{l}\text { Modification } \\
\text { of predicate }\end{array}$ \\
\hline PTRANS & $\begin{array}{l}\text { bring } \\
\text { take }\end{array}$ & $\begin{array}{l}\text { GOal- } \\
\text { PHYS - LOC }\end{array}$ & & $\begin{array}{l}\text { REPL by } \\
\text { 'arrive*' }\end{array}$ \\
\hline MTRANS & $\begin{array}{l}\text { bring } \\
\text { take }\end{array}$ & $\begin{array}{c}\text { EXPER-HUMU } \\
\text { MENT - SUBJ }\end{array}$ & & $\begin{array}{l}\text { REPL by } \\
\text { 'attain*' }\end{array}$ \\
\hline CAUSE & $\begin{array}{l}\text { force } \\
\text { compel }\end{array}$ & . & $\begin{array}{l}\text { ADDition of a } \\
\text { MANNer case } \\
\text { with } \\
\text { 'inevitably*" }\end{array}$ & DELetion \\
\hline Possession & have & $\begin{array}{l}\text { POSS-HUM, } \\
\text { OBJ-HUMU } \\
\text { NATURal-- } \\
\text { phenomenon }\end{array}$ & $\begin{array}{l}\text { CHANGE } \\
\text { from POSS } \\
\text { to EXHIBition }\end{array}$ & $\begin{array}{l}\text { REPL by } \\
\text { 'exist*' }\end{array}$ \\
\hline
\end{tabular}


preferable form in Japanese even in the case the POSSessor is a HUMan unless the expression is like that 'a living POSSessor has a PHYSical OBJect in his hand? Some examples are shown in Table 6 .

\section{Example 6}

By case transformation shown in Table 6 , the following three English sentences

(1) 'A few minutes walk brought me the place'

(2) "The fact led him the conclusion'

(3) 'We had heavy snowfall last year'

are translated into Japanese sentences corresponding to

(1') 'By walking for a few minutes, we arrived at the place'

(2') 'From the fact, he attained the conclusion'

(3') 'There was heavy snowfall last year"

respectively.

In sentence (1), the agent with the category PTRANS action is verbalized in construction of the case structure, and renamed as the case

'MEANS' by the case transformation.

\subsection{Case transformation for target-clause ordering}

This section describes a case transformation by which the order of clauses of a target sentence corresponds to that of a source sentence to some extent in the locative or temporal sense.

In general, an English sentence is translated into a Japanese sentence so that dependency relations in surface structure such as those of subordinate clauses to the principal clause do not change so much for preserving the stream of the main subjects included in successive English sentences.

However, there are several exceptions. One of them has a comparatively definite type in sentential forms as well as in translation. A certain kind of English sentences do not correspond to natural Japanese sentences unless the relation of a subordinate clause to the principal one is reversed. For example, if a resultant state is contained as a dependent in an English sentence which describes an action or a state, each of them is generally described in Japanese as a dependent in a sentence which describes the result as shown in Example 7 .

\section{Example 7}

Two English sentences

'He awoke to find himself in a strange room' and

'The problem was so difficult that no man could solve it"

are translated to Japanese sentences corresponding to

'When he awoke, he found himself in a strange room, and

'Because the problem was so difficult, no man could solve it'

respectively.

The first of the above translation is done by the case transformation;

(PRED-PERCEP.ACT: awake, EXPER-HUM: he, RESULTEVENT: (PRED-PERCEP.ACT : find, EXPER-HUM: he, OBJ-HUM: himself, LOC-PHYS.LOC:in-room(D )))

$\rightarrow($ PRED-PERCEP-ACT: find, EXPER-HUM: he, OBJ-HUM: himself, LOC-PHYS.LOC: in-room (D), TIME-INSTANT : when (PRED-PERCEP.ACT : awake, EXPER-HUM:he))

where $D:=O B J-P H Y$ LOC: *, DET : indef, PRED-ATTR: strange,

The other exceptional translations do not have definite type, but are desirable for readability of translated sentences when English sentences have some long adjective on adverbial subordinate clauses or phrases after their rather short principal clause. These subordinate clauses have generally more concrete and essential meaning than the principal clause.

In such cases, if translation is done in the ordinary way so that the relation of subordinate clauses to the principal clause remains unchanged, the generated Japanese sentence tends to have a long essential subordinate part followed by a short and rather introductory part of the principal clause. The Japanese sentences thus obtained will often bring about difficulties in immediate comprehension. Furthermore, when a part of subordinate clauses is referred in the next sentence, the immediate identification of the anaphora will not be so easy owing to increase of distance from the referring part as shown in Fig. 3.

In such cases a continuative translation is more preferable. ${ }^{6}$ It assigns a location succeeding to the principal clause for an equivalent of the subordinate clause. The subordinate clauses are classified to adverbial clauses and adjective ones.

In the former case, the subordinate clause is qualified as a sentence or a coordinate clause in a continuative translation. For a coordinate clause, the coordinate conjunction is preceded which is determined by the case label of the adverbial clause and more precisely by the preposition or the subordinate conjunction.

In the latter case, syntactic roles of a principal clause and a relative clause are reversed through a modified term as follows;

$$
\begin{gathered}
\left(K_{1}: t_{1}, K_{2}: t_{2}, \ldots, K_{k}: t_{k}\left(K_{1}^{\prime}: s_{1}, \ldots, K_{i}^{\prime}: *,\right.\right. \\
\left.\longrightarrow\left(K_{i}^{\prime}: t_{k}\left(K_{1}: t_{1}, K_{2}: t_{2}, K_{l}^{\prime}: s_{l}\right)\right) K_{k}: *\right), \\
\left.K_{1}^{\prime}: s_{1}, \ldots, K_{l}^{\prime}: s_{l}\right)
\end{gathered}
$$

where the double-underlined case means that a thematic fronting and addition of a certain thematic postposition is done for the underlined case in generation of a Japanese sentence 


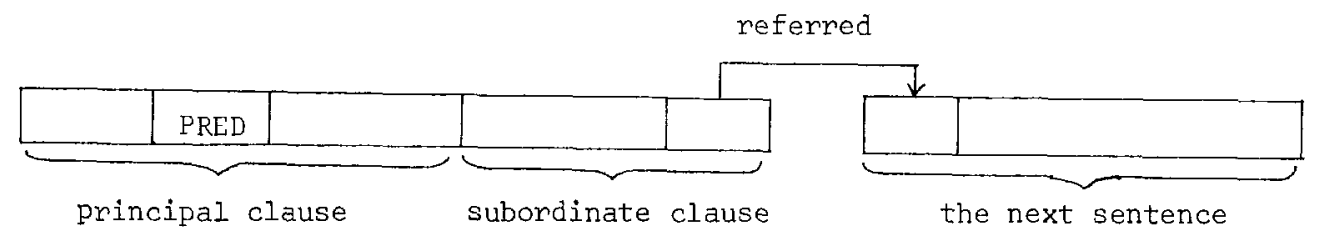

(a) a source sentence

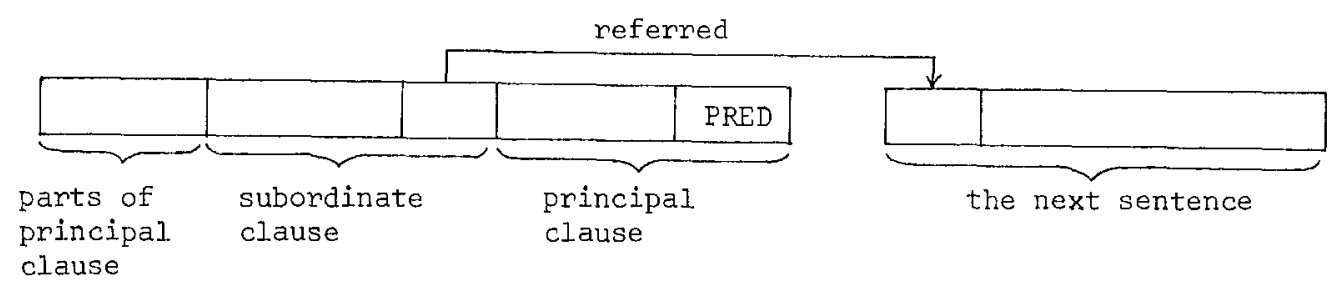

(b) a Japanese sentence

Fig. 3 Onder of subordinate and principal clauses

from the transformed case structure.

\section{Example 8}

\section{Two English sentences}

'Science deals with sense impressions which are similar to make universal agreement possible' and

'That all men are all equal describes a proposition to which no sane human being has ever been given his assent'

are translated into Japanese sentences corresponding to

'Sense impressions which science deals with are similar to make universal agreement possible' and

'To a proposition which describes that all men are all equal no sane human being has ever been given his assent' respectively,

A sentence which contains a kind of appositions is also transformed as follows;

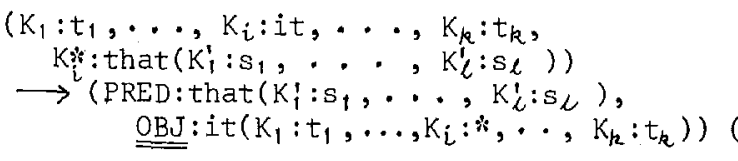

where $K_{i}^{*}$ is an apposition case to a case $K_{i}$.

Example 9

An English sentence

'We should make it clear that they lead the same conclusion'

is translated to a Japanese sentence corresponding to

That we should make clear is that they lead the same conclusion'.

\section{Conclusion}

The case structures obtained by parsing on the transformed case structure are expanded in an appropriate term-order by a Japanese grammar under various control of the involved parameters.

Some experimental results show that this approach is effective to dissolve multi-syntactic and semantic category problems of words and phrases and efficient to transform case structures.

From the view point of more precise and multi-lingual translation, it is desirable that more precise, detailed and standardized definition is established for case structures and hierarchic category systems and also their codes are attached to some word dictionaries. It will not be impossible as far as mechanical translation of technical papers is concerned.

\section{References}

1. Wilks,Y.jAn artificial intelligence approach to machine translation', Schank and colby (eds.), Computer models of thought and language, San Francisco, Freeman,p.114,(1973).

2. Vauquois, B., 'Aspect of mechanical translation in 1979', GETA, Univ.Grenoble, (1979).

3. Hornby, A.S., 'Guide to patterns and usage in English', second edition, London, Oxford University Press, (1975).

4. Bruce,B., 'Case systems for natural language', Artificial Intelligence, Vol.6,p.327,(1975).

5. Kunihiro,T., 'Structural semantics', Sansei-do,(1976), (written in Japanese).

6. Bekku,S.,'Study of translation', Yashio-shuppan-sha, (1976), (written in 